\title{
Does Compulsory Voting Distort Electoral Outcomes?
}

\author{
Gary Johns
}

$\mathrm{I}$

S compulsory voting 'the great guarantee of truly democratic elections' that Neville Wran (1997:1) believes it is, or should the obligation to vote be converted into a right to vote or not to vote? This challenge is now upon the electorate following the recommendation by the Parliamentary Joint Standing Committee on Electoral Matters (1997:xx) that Section 245 of the Commonwealth Electoral Act, which provides for compulsory voting, be repealed.

Australians do in fact have the right not to vote, but few know it. A voter is not obliged to cast a vote by marking the ballot paper, and can comply with the law merely by returning the ballot to the ballot box. Although this latter claim is open to debate (Twomey, 1996:209), the secret ballot makes detection of an unmarked ballot difficult, if not illegal, and thus ensures that voters need not vote. However, the advertising accompanying the election for the Commonwealth parliament, and the emphasis on making a formal vote, give voters the strong impression that it is compulsory to vote. Indeed, more than 95 per cent of Australians do vote on a regular basis, and have been doing so since the 1925 election (Parliamentary Research Service, 1994/95:85).

The cost to the individual of compulsory voting is small, certainly when compared with, for example, that of compulsory jury service. There appear to be few signs of civil disobedience associated with compulsion; and compulsory voting appears to be popular: 74 per cent of all candidates at the 1996 Commonwealth election favoured compulsion (Jones et al., 1996:40), as did 70 per cent of the electorate (Mackerras \& McAllister, 1996:Figure 1).

Debate about compulsory voting tends to concentrate on the moral issue of whether voting should be obligatory (Jones, 1996) or a right that one may choose not to exercise (Minchin, 1996). Yet both supporters and opponents of compulsory voting are also concerned about a number of issues that are open to empirical and theoretical investigation. They are concerned about three issues in particular: the level of voter turnout; any bias in the vote associated with a given turnout; and any impairment directly associated with either compulsory or voluntary voting. This note explores these issues and tries to come to some conclusions about them. 


\section{Voter Turnout under Voluntary Voting}

In response to a report that 88 per cent of Australians would vote if voluntary, Senator Nick Minchin, the Liberal Party's main advocate of voluntary voting, stated that he was delighted 'that such an overwhelming majority of Australians would freely choose to exercise their right to vote without being forced to do so by law. Nothing could better demonstrate how unnecessary compulsory voting is...' (quoted in Jackman, 1997:1). The assumption is that a higher turnout is preferable to a lower turnout.

If compulsory voting were abolished in Australia, it is generally agreed that turnout would drop. But by how much? Would it be nearer the 59.2 per cent turnout of eligible voters in the 1922 Commonwealth election that sparked the legislative introduction of compulsion in the first place, or the 88.3 per cent voluntary turnout in New Zealand in 1996 (Mackerras \& Smiley, 1997:632)?

The voluntary postal ballot for the 1998 Constitutional Convention in Australia recorded a turnout of just under 47 per cent. This figure is probably lower than it would be for a Commonwealth parliamentary election, which voters may take more seriously, although the requirement that voters attend a polling booth in order to cast a ballot is more time-consuming and may dissuade even more potential voters under a voluntary vote than the postal version. Nevertheless, the experiment suggests that a substantially lower turnout could be expected under a voluntary ballot. Jackman (1997:42) estimates, based on non-response and estimation of measurement errors of Australian survey data, that with the abolition of compulsion 'substantially lower rates of voluntary turnout would eventuate, perhaps as low as those countries like Japan or the US, in the 50 per cent to 60 per cent range'.

A change of voting law in Austria for its 1986 federal election fortuitously made possible a comparison of turnout in the Austrian province of Carinthia, which introduced mandatory voting for the election, and in surrounding provinces which remained voluntary. With a turnout of 92 per cent before the change to the law, Carinthia was already an highly participatory electorate. Even so, the rate jumped by 2.2 percentage points, and by 5 per cent relative to other provinces (Hirczy, 1994:74). This study suggests that the abolition of compulsion, in the first instance at least, would lead to a fall in turnout even where there was a political culture of high turnout.

\section{Turnout and Bias}

In what ways, if at all, is democracy harmed by a low turnout?

Compulsion and information. It is a reasonable assumption that any loss of information is detrimental to democracy. Democracy reflects the information that citizens have about politics, sufficient at least to allow them to vote, whether in their own self-interest or for the common good. But, as Lau and Redlawsk (1997:585) remind us, only a tiny minority of citizens live up to the ideal of participation that democratic theorists like J.J. Rousseau and J. S. Mill recommended. Other com- 
mentators argue that political indifference is a good thing, since it promotes stability by dampening the impact of the ideologues. Presumably this means that the ignorant and the indifferent have to express those 'views' by voting, and that to this end it can be held that 'compulsory voting affects political culture in a conservative way' (Parish, 1992:18).

In a study of voters in the US, where voting is voluntary, Lau and Redlawsk (1997:586) found that a surprisingly high 75 per cent of voters voted 'correctly', in the sense that the votes they cast were 'the same as the choice which would have been made under conditions of full information'. Would the percentage of 'incorrect' votes be even higher under compulsion? The study cannot tell us, but it does suggest a probable loss of 'correct' votes among those who do not vote: that is, a loss of valuable information from the democratic process.

Partisan bias. Mackerras and McAllister (1996) suggest that compulsory voting has a built-in bias against right-wing parties and in favour of left-wing and minor parties. In Australia, support for compulsion by the ALP, the Australian Democrats and the Greens suggests that this is indeed the case. But this is surely just the obverse of the bias against left-wing parties that would follow an abolition of compulsion. McAllister (1986:92) has estimated that, if turnout fell to 1922 proportions, Labor would lose nearly 4 per cent and the Liberals would gain 2 per cent on the 1977 election result. For the 1996 result, Jackman (1997:40) concludes that, 'as turnout diminished, the Liberals' share of the vote could be as much as 7.4 percentage points higher than the ALP's'.

The vote that the ALP receives as a result of compulsion could be viewed as an error that voluntary voting would avoid. But it should more accurately be viewed as valid opinion that would otherwise go unmeasured. Only the complete population supplies the accurate picture of the electorate's view; any move that would lower the turnout would almost certainly provide a biased sample of the voters' wishes. A return to voluntary voting thus risks a loss of collective judgment.

\section{Does Compulsion Impair the Vote?}

One measure of impairment associated with compulsory voting is the level of informal voting, which in Australia is high by international standards. However, it is generally accepted that this is the result of the interaction between compulsory voting, the complexities of the electoral system like preferential voting and differences in the voting rules for different elections, and the presence of a large number of non-English speaking migrants (McAllister, 1993:23). At the 1996 Commonwealth election, 3 per cent of the votes cast were informal; compulsory voting may account for a part of that figure, but even if it accounted for all of it, it hardly compares with a potential (and arguable) 30 per cent impairment to the vote under voluntary voting, if that proportion chose not to vote.

There are at least two important theoretical considerations. Shapiro (1990:112) desires to achieve a 'thoroughgoing pluralism of dispersed preferences'. Democracy as majority rule was originally an 'oppositional' ideal, an instrument for oppos- 
ing the elite. In the Australian context, that elite could arguably be defined as an intelligentsia that exercises an undue influence on democratic politics. Such a tendency would be enhanced if less articulate citizens failed to vote. Democracy as an oppositional mechanism should be at its most powerful when the greatest number of potential non-voters vote, that is, when the dispersal of preferences is at its greatest.

Brennan and Lomasky (1993:225) advance a principle of 'responsible civic conduct' that could be interpreted as favouring compulsion. Their arguments opposing the secret ballot are also relevant. They claim that the secret ballot inhibits a culture of open discussion and leads to a monopoly of discussion by parties and journalists; only an open ballot can filter out anti-social voting motives like flippancy or meanness. They imply that the suffrage should be restricted to those who 'have on hand an array of publicly acceptable reasons to justify one's actions' (Brennan \& Lomasky, 1993:219). But if only such people voted, the likely loss of 'correct' votes would be high. As well, it is often the least articulate who are prone not to vote (McAllister 1986:91), but their contribution as an oppositional force can provide for a more thoroughgoing pluralism and in that sense encourages responsible civil conduct.

The one element of compulsion that does bear repeal is the exhaustive preferential ballot, which in effect forces voters to make a choice between the major parties. Rydon (1997:177) has suggested that the low turnout at the 1922 election may have been caused by a change from first-past-the-post to preferential voting, which some voters found difficult or objected to. In a sense, complexity begat compulsion. The proponents of the repeal of compulsion, however, have no intention of ditching the exhaustive preferential vote (there was no dissent on the issue in the Joint Standing Committee Report).

Preferential voting is a reasonable system, ensuring that the least number of votes are wasted (Taylor \& Johnston, 1979:50). However, in 1996 Albert Langer drew attention to the fact that it was possible to cast a formal vote that avoided a choice between the major parties, since, under $\mathbf{5 . 2 7 0}$ of the Commonwealth Electoral Act, a vote is formal even when a preference number is repeated and a box left unfilled. Yet Langer was gaoled because he committed the offence of advocating voting in a way that did not accord with the instructions on the ballot paper. This drives compulsion to the extreme, and increases the risk of an 'incorrect' vote being cast (one not reflecting the voter's opinion). There is a vast distinction between a system of compulsory voting where voters are required only to deposit a ballot in the box, and one where they are compelled to allocate preferences to all candidates. As Twomey (1996:201) has argued, where voters are compelled to express a preference for certain candidates they do not wish to, they are in effect being forced to lie.

The Joint Standing Committee recommended closing the 'Langer loophole', but only because it exploited a contradiction in the voting instructions in the Act,

${ }^{2}$ It could be as forcefully argued that the secret ballot protects the voters from interference in casting their votes: which is, of course, why it was introduced. 
which allowed for more than one method of casting a formal vote. If the recommendation for the repeal of compulsory voting had been accompanied by a recommendation for substituting compulsory exhaustive preferential voting with optional preferential voting, it might have been more credible. As it is, it looks like an exercise in partisan politics.

\section{References}

Brennan, G. \& L. Lomasky (1993), Democracy and Decision, Cambridge University Press, Cambridge.

Hirczy, W. (1994), 'The Impact of Mandatory Voting Laws on Turnout: A Quasi-experimental Approach', Electoral Studies 13: 64-76.

Jackman, S. (1997), 'Non-Compulsory Voting in Australia?: What Surveys Can (and Can't) Tell Us', unpublished paper, Research School of Social Sciences, ANU, Canberra.

Joint Standing Committee on Electoral Matters (1997), The 1996 Federal Election, The Parliament of the Commonwealth of Australia, Canberra.

Jones, G. (1996), 'Compulsory Voting: Enforcing a Responsibility to Society', The Parliamentarian 77: 24.1-3.

Jones, R., I. McAllister \& D. Gow (1996), Australian Candidate Study 1996, Social Science Data Archives, Research School of Social Sciences, ANU, Canberra.

Lau, R. \& D. Redlawsk (1997), 'Voting Correctly', American Political Science Review 91: 585-98.

Mackerras, M. \& R. Smiley (1997), 'Three October 1996 Week-end Elections', pp. 599-636 in Proceedings of the 1997 Annual Conference, Australasian Political Studies Association, Flinders University, Adelaide.

Mackerras, M. \& I. McAllister (1996), 'Compulsory Voting, Party Stability and Electoral Bias in Australia', paper presented to American Political Science Association, San Francisco.

McAllister, I. (1986), 'Compulsory Voting, Turnout and Party Advantage in Australia', Politics 21: 89. 93.

- (1993), 'Institutions, Society or Protest? Explaining Invalid Votes in Australian Elections', Electoral Studies 12: 23-40.

Minchin, N. (1996), 'Compulsory Voting: A Denial of Rights, a Detriment to Democracy', The Parliamentarian 77: 244-8.

Parish, R. (1992), 'For Compulsory Voting', Policy 8(1): 15-18.

Parliamentary Research Service (1994/95), Compulsory Voting, Department of the Parliamentary Library, Canberra.

Rydon, J. (1997), 'Compulsory Voting and Compulsory Preferences', pp. 175-7 in C. Copeman \& A. McGrath (eds), Comupt Elections, H. S. Chapman Society, Sydney. 
Shapiro, I. (1990), 'Three Fallacies Concerning Majorities, Minorities, and Democratic Politics', pp. 79-125 in J. Chapman \& A. Wertheimer (eds), Majorities and Minorities, New York University Press, New York.

Taylor, P. \& R. Johnston (1979), Geography of Elections, Croom Helm, London.

Twomey, A. (1996), 'Free to Choose or Compelled to Lie? The Rights of Voters After Langer v Commonwealth', Federal Law Review 24: 201-20.

Wran, N. (1997), 'The Australian Republic', Whitlam Lecture, ACTU, Melbourne (19 November).

The author is grateful to two anonymous referees and the editor for their comments on an earlier draft. 